ISSN: 2277-3754

ISO 9001:2008 Certified

International Journal of Engineering and Innovative Technology (IJEIT)

Volume 10, Issue 5, November 2020

\title{
The Role of Insurance Companies to Road Traffic Safety in CAMEROON
}

${ }^{1}$ George Elambo NKENG, ${ }^{2}$ Jean François WOUNBA, ${ }^{3}$ Stephen Kome FONDZENYUY, ${ }^{4}$ Usami Davide SHINGO, ${ }^{5}$ Persia LUCA

${ }^{1}$ Professor, Director of National Advanced School of public works, Ministry of public works, Cameroun.

${ }^{2}$ Department of Town planning, National Advanced School of Public Works, Ministry of public works, Cameroun.

${ }^{3}$ Department of Civil Engineering, National Advanced School of Public Works, Ministry of public works, Cameroun.

${ }^{4}$ Research Center for Transport and Logistics, Sapienza University of Rome via Eudossiana, (Rome). ${ }^{5}$ Director of Research Center for Transport and Logistics, Sapienza University of Rome via Eudossiana, (Rome).

\begin{abstract}
Although road safety is generally based on the areas of prevention, there has been an increasing emphasis on the relationship between insurance, road accidents and road safety. This study was designed to investigate the role of insurance companies to road safety in Cameroon. A sample survey data was used to examine the participation of insurance companies to road safety in Cameroon. The qualitative data analysis carried out revealed that Cameroonian insurance companies' are mostly involved in compensating road victims as way to promote road safety, which is their businesses and their primary objectives are not to reduce road accidents, but however, driver training (the insured), education and publicity and to a lesser extent traffic law enforcement were carried out by to improve road safety. The bonus malus system was identified to be an ineffective policy in promoting road safety due to the instability of the insured. This study has revealed the many different ways by which Cameroon insurance companies could be involved in road safety and in particular the potential benefits of taking part in road safety issues. Consequently, there is an urgent need for active participation of these companies. The usage-based insurance policies appear to be the best 'good practice' recommended to Cameroon insurance companies in terms of the level of challenge and level of priority, in addition to its safety and insurance benefits.
\end{abstract}

Keywords: Road Safety; Insurance company; Accident Prevention; insurance policies.

\section{INTRODUCTION}

Despite the substantial improvements in road safety and adoption of a safe systems strategy in the past decade, there has been no reduction in the number of road accidents in any low-income country since 2013 according to the global status report on road accidents[1]. The trends of road accidents continue to increase in all developing countries and in Cameroon; World Health Organisation estimates road traffic fatalities of 2016 at 7066, with a rate of 30.1 per 100000 populations[1]. The monitoring system in Cameroon is primarily focused on police documenting deaths from police stations in the country [2].

Manuscript received: 20 October 2020

Manuscript received in revised form: 16 November 2020

Manuscript accepted: 02 December 2020

Manuscript Available online: 15 December 2020
In most countries, economic losses resulting from incidents by the road are considerably higher than in developed aid, ranging from $1 \%$ to $3 \%$ in GDP shares and US\$ 65 billion in low- and middle-income countries [3]. In virtually all countries of the world, reductions in the number of people killed and injured seriously on routes are of utmost importance to communities with the goal to minimise the personal and economic burden of the injured and their flowon consequences for families and the wider community[3] [10].

The constant challenge of road safety is that drivers who, as a whole, are overconfident in their capacity are highly dependent on the choices and actions of vehicles [4]. Regulations can try to control drivers' choices and conduct can affect road safety greatly. In the past 10 years, car insurance providers have become heavily active in road safety engineering programmes. While insurance companies traditionally engage in driver training and vehicle design initiatives, insurance undertakings initiatives aimed at the road safety engineering aspect are quite a recent trend [5].

Engine insurance is capable of being a good tool for personal liability promotion. The relationship between the impacts of an accident and the cost-effectiveness of these effects, if efficiently conveyed, would lead progressively to improved movement [6]. With the implementation of telematics, in-vehicle technology which insurers will use to track vehicle use, insurer's ability to control how we travel and how far we drive. As a consequence, insurers give policyholders opportunity to drive less safely (UBI) products.[4] Creative insurance policy could have an impact on safety in conjunction with its design.[7] This may also have a major impact. Pay-as-you-drive schemes (PAYD) and the pay-how-you-drive (PHYD) are covered in insurance plans focused on vehicle use (UBI) with potential upcoming versions on PAHYD [8].

In addition to the activities followed by many insurance firms, research conducted by several scholars shows that insurance companies could also be interested in road safety through insurance schemes such as Travel actions and insurance driver-based behaviour[7]-[9]. Pricing of driving incentives [10/12]. Funds for road safety [13]; road safety 
ISSN: 2277-3754

\section{ISO 9001:2008 Certified}

\section{International Journal of Engineering and Innovative Technology (IJEIT)}

Volume 10, Issue 5, November 2020

research and information management [13]; Rules, life insurance). From her statistics there are 16 insurance application, promotion [12]. road safety support and companies involve in damage claims, with most of these sponsorship[12].Apart from highlighting the role played by insurance companies to road safety, authors have also commented on the effectiveness of these practice/role and in addition pointed non- effective measures. For example, the influence of motor insurance premiums on driver conduct and road safety has shown [13], with a growing value of motor assurance premiums, that the proportion of drivers in road accidents is decreasing. In addition, drivers who demand more motor insurance are more likely to be culpable of incidents in traffic [12], [13]. Bonus Malus has faced many critiques because it decreases the likelihood of recorded crashes [13] and thus the reporting of crashes. The system has not been successful. Studies on the effect of Cohen \& Dehejia's automobile insurance and accident liability laws [12] have shown that automotive insurance has a moral risk expense, which results in more fatality in traffic; that the decreases in accident liability caused by non-fault liability legislation contribute to an increase in the number of fatalities in the car (estimated to be on the order of 6 percent).

Financial risks resulting from vehicle operations can be best handled with compulsory insurance in place. The harm caused by incidents to personal property, public property and personal injury can be treated without putting an unfair burden on private or public institutions and organizations. Insurers are constantly looking for new ways to minimize the number and severity of road accidents because insurance and traffic crises are natural allies, both as part of their social responsibility pledge and efforts to reduce claims volume.

This research was developed by the World Bank in order to determine the socio-economic costs of Cameroon road accidents. The global goal of the research was to detect how insurance firms from Cameroon help minimise the road trauma burden to avoid and reward road accidents. In line with this initiative. As specific objectives in this study, we aimed to:

- Examine the insurance industry involvement in road safety in Cameroon;

- Provide potential benefits of implementing different strategies identified from literature, as well as measuring the transferability of good practices identified in the literature.

This investigation is therefore undertaken to examine the promotion of road safety and interventions by insurance firms in Cameroon. How will they help reduce the risk and effects of road trauma in order to protect the lives of millions of them and protect the human capital needed for the country's growth?

\section{METHODOLOGY}

\section{A. Site and Population of Study}

According to the 2018 statistics report by ASAC (Association of Cameroon insurance companies), insurance companies in Cameroon are divided into two main branches, 'Assurance Dommage' and 'Assurance Vie' (damage and companies having headquarters in the economic capital of the country, Douala, which was our study site. In order to choose the target population, the main factors considered were longevity since start of activities, companies with the highest capital (based on ASAC 2018 statistic), geographical location (companies in close proximity, easily situated), and popularity. With these factors we shortlisted 11 companies.

Despite our target population of 11 insurance companies, we had only 03 participating companies, 02 of the companies participating fully, and partial information obtained from the third company. As concern the two participating companies, one of the participating companies is a co-insurance pool, the public passenger transport pool created by ASAC that has been in place since august 2009 and involves a grouping of insurance companies participating in the field of insurance operations covered by civil liability. It is a body where all automobile risk relating to the use of public transport for travellers and tourist (urban and inter-urban transport vehicles, including the transport of staff and students, motorcycles, taxis and car rental vehicles) are jointly managed. The second insurance company that started operational on September 2007, is amongst the companies involved in managing damage claims, having a total market of 5 billion 172 million FCFA and specifically 1 billion 182 million FCFA for civil liability coverages. Taking into consideration the characteristics of the above companies, the information obtained could be conclusive for the other companies.

However, in this research, it was necessary to consider other sources of data, due to the reluctance of insurance companies to pool data. As such, data was collected from insurance experts and specialist who collectively gave a general overview on the involvement of Cameroon insurance companies in road safety, based on their experience (both in the teaching domain and in the practising/ working domain).

\section{B. Data Collection Sources and Techniques}

\section{Data Sources}

Primary data was collected from the experts and the 03 insurance companies, which was mainly qualitative as it had no numerical characteristics. The primary data collected from the insurance companies involved different departments, claims department heads, marketing department heads, human resource department head and the technical department. The data collected was mainly qualitative as it had no numerical characteristics.

\section{Techniques}

The choice on research technique depends whether the research is qualitative, quantitative or mixed [13]. In this study, we used Questionnaires and interview to collect data.

\section{Questionnaires}

To make a choice of the type of questionnaires to employ, variety of factors have to be considered, firstly, the characteristics of the respondents from which we have to collect data and secondly the importance of reaching a 
ISSN: 2277-3754

\section{ISO 9001:2008 Certified}

\section{International Journal of Engineering and Innovative Technology (IJEIT)}

Volume 10, Issue 5, November 2020

particular person as respondent. As to the structure of our questionnaires and type of data needed, our respondents were to consist of personnel from different insurance departments. Due to the busy schedule of personnel (respondents) at their work site, self-completed questionnaire was preferred. The target insurance companies were visited and questionnaires delivered. These questionnaires were later collected after receiving phone call from the respondents.

\section{Interview}

In this research we carried out responses to interviewercompleted questionnaires in one company and it was semistructured. This category of interview was used because only the technical department of the company was available, who was not capable to answer questions concerning other departments. The interview carried out focused on the company's role in road safety.

\section{Data Analysis}

A significant part of the overall survey activity is data collection and analytics. The SPSS (Statistical Kit for Social Sciences), version 20.0, quality analysis for questionnaires and interview data (primary data) was carried out in this investigation. The stages of qualitative data analysis and processing employed in this study, consisted of data editing, data coding, data files and data analysis in SPSS.

In General, to achieve the objective of this study the steps involved were: provide a background research on the existing role of insurance companies to road safety, identify good practices and non-effective measures, use the results to examine the situation in Cameroon, measure the transferability of these good practices and lastly identify the best performing practice in terms of transferability and potential benefits.

\section{RESULTS}

\section{A. Results of Qualitative Analysis (Role of Insurance Companies to Road Safety in Cameroon)}

In line with our specific objective, a literature review was carried to know how insurance companies participate in road safety. The results showed that they can participate through: pricing incentives for safe driving (premium basis, bonus malus system); insurance policies (like Pay As you drive and Pay How You drive); compensation and rehabilitation (compensation benefits, liability); national road safety policy; road safety funding and sponsorship (sponsorship of specific interventions such as driver training and education, publicity, vehicle safety etc.); road safety research (use of onboard diagnostics, black boxes, whiplash, geosostat etc.); Data management. These results were obtained from a variety of sources (authors) and a variety of case studies such as: ANIA (Italian Association of Insurance Companies) involvement in road safety; the association of Spanish Insurers (UNESPA).

The results of this review were used to evaluate the situation in Cameroon, specifically in the headings below. The results obtained were classified into two, those provided by the insurance companies and those given by the experts

\section{Contributions to Reduce Accidents}

Table 1. Insurance company's contributions to reduce road accident

\begin{tabular}{|c|c|c|}
\hline $\begin{array}{l}\text { Contributions to reduce } \\
\text { road safety }\end{array}$ & Frequency & Percent \\
\hline Education of insured & 3 & 100 \\
\hline $\begin{array}{ll}\text { Sensitization } & \text { through } \\
\text { Social media } & \end{array}$ & 1 & 33.3 \\
\hline $\begin{array}{ll}\text { Sensitization } & \text { through } \\
\text { Social outings } & \end{array}$ & 1 & 33.3 \\
\hline $\begin{array}{l}\text { Training of workers on } \\
\text { road safety aspects }\end{array}$ & 1 & 33.3 \\
\hline Law enforcement & 1 & 33.3 \\
\hline
\end{tabular}

Note: The frequency represents the number of companies involved in a specific practice, with the percent representing the percentage of insurance companies involved in that practice.

Expert response: According to this response, termed the 'general response' in this survey, Cameroonian insurance companies are simply pure traders, because they are not very interested in the social aspect, so no public awareness campaign to reduce road accidents. The few actions available called "Help" aim to track vehicles that drive without insurance.

\section{Pricing Incentives for Safe Driving}

Table 2. Pricing incentives for safe driving.

\begin{tabular}{|c|c|c|}
\hline Bonus-malus system & Frequency & Percent \\
\hline Valid & 3 & 100.0 \\
\hline
\end{tabular}

Note: The frequency represents the number of companies involved in a specific practice, with the percent representing the percentage of insurance companies involved in that practice.

Expert response: Bonus and penalty (malus) are part of the car tariff, but it is difficult to apply these advantages or sanction by insurance companies due to the instability of car customers who change companies with each renewal. In addition, all automobile tariffs are fixed by Ministry of Finance and these tariffs don't reflect the travel and driving behavior of travels.

\section{Road Safety Research}

The results of road safety research were divided into two headings, technologies to improve road safety and data management.

\section{Technologies to Improve Road Safety}

Table 3. Promotion of new technologies to improve road safety.

\begin{tabular}{|l|l|l|}
\hline $\begin{array}{l}\text { New Technologies to improve } \\
\text { road safety }\end{array}$ & Frequency & Percent \\
\hline None & 1 & 33.3 \\
future plans & 1 & 33.3 \\
yes, but partially implemented & 1 & 33.3 \\
Total & 3 & 100.0 \\
\hline
\end{tabular}


ISSN: 2277-3754

\section{ISO 9001:2008 Certified}

\section{International Journal of Engineering and Innovative Technology (IJEIT)}

Volume 10, Issue 5, November 2020

Note: The frequency represents the number of companies involved in a specific practice, with the percent representing the percentage of insurance companies involved in that practice.

Expert response: no new technology is being practice or applied to ameliorate road safety.

\section{B. Data Management}

Table 4. Different data collection sources for insurance companies.

\begin{tabular}{|l|l|l|l|l|}
\hline $\begin{array}{l}\text { Different sources of data for } \\
\text { insurance concerning road } \\
\text { safety }\end{array}$ & \multicolumn{2}{|l|}{ Responses } & Percent of \\
\cline { 3 - 4 } & $\mathrm{N}$ & Percent & \\
\hline Police/ Gendarmerie & 3 & 37.5 & 100.0 \\
Medical institution & 1 & 12.5 & 33.3 \\
Justice & 1 & 12.5 & 33.3 \\
others (insured) & 3 & 37.5 & 100.0 \\
Total & 8 & 100.0 & 266.7 \\
\hline
\end{tabular}

Note: The percent represents percentage of a given data source with respect to others, $\mathrm{N}$ indicates the number of companies using a particular data source, with the percent of cases representing the percentage of insurance companies using the given data source.

Expert response: According to the general response, data is received/collected from police/gendarmerie, justice and the insured but not from medical institutions.

Table 5. Furnishing of data for road safety purposes.

\begin{tabular}{|c|l|l|l|}
\hline $\begin{array}{l}\text { Furnishing data for road } \\
\text { safety purposes }\end{array}$ & \multicolumn{2}{|l|}{ Responses } & $\begin{array}{l}\text { Percent of } \\
\text { Cases }\end{array}$ \\
\cline { 2 - 3 } & $\mathrm{N}$ & Percent & \\
\hline Police/ Gendarmerie & 0 & 0 & 0 \\
National statistics & 3 & 100 & 100 \\
$\begin{array}{c}\text { Researchers } \\
\text { Total }\end{array}$ & 0 & 0 & 0 \\
\hline
\end{tabular}

Note: The percent represents percentage of a given data source with respect to others, $\mathrm{N}$ indicates the number of companies furnishing a particular data source, with the percent of cases representing the percentage of insurance companies furnishing the given data source.

Expert response: The information on claims data is only being furnished for national statistics purposes and no company has furnished data for the past years on road safety.

\section{Compensation}

Firstly, the results obtained for the different compensation payments shows that, any harm to a person physical, moral or economic is always compensated and as stipulated in the CIMA code. According to the results, the different prejudice cases compensated are:

\section{- $\quad$ The Direct Victim}

The partial functional deficit; Loss of current professional earnings (article 259 of the CIMA code); The suffering endured (article 262 of the CIMA code); Cosmetics/aesthetic damage (article 262 of the CIMA code); Career loss (article
263 of the CIMA code); Third party assistance (article 261 of the CIMA code).

\section{- In Case of Death of Victim}

Funeral costs; Economic damage to the beneficiaries of the deceased (article 265 of the CIMA code); Non-pecuniary damage to the beneficiaries of the deceased (article 266 of the CIMA code).

The results obtained from the procedures to accelerate compensation of victims show that, with regard to material damage, the insurance companies have signed an agreement called the IDA Convention '(Direct compensation of insured persons) which allows the repair of material damage to their insured parties to be accelerated before appealing to the responsible insurer.

\section{Involvement in National Road Safety Strategy}

The result from the primary source and general response shows that insurance companies are not involved in activities of road safety, because the public authorities concern in national road safety issues don't associate the insurers.

\section{Other Contributions to Improve Road Safety}

Table 6. Other contributions by insurance companies to improve road safety.

\begin{tabular}{|l|l|l|l|}
\hline $\begin{array}{l}\text { Other contributions to } \\
\text { improve road safety }\end{array}$ & \multicolumn{2}{|l|}{ Responses } & Percent of \\
cases
\end{tabular}

Note: The percent represents percentage of a given practice with respect to others; $\mathrm{N}$ indicates the number of companies involved in a particular practice, with the percent of cases representing the percentage of insurance companies involved in a given practice.

\section{Results of Potential Benefits of Involvement in Road Safety}

As part of the specific objectives in this research, it was important to highlight the safety benefits of involving in road safety. Recommendations are not always enough to show how a situation can be solved, but recommendations supplemented with the benefits of applying it gives value to the recommendations. So, it was very necessary to outline these safety benefits. Table 7 below summarizes the benefits for each recommendation, according to a series of authors (Shown in Appendix). 
ISSN: 2277-3754

\section{ISO 9001:2008 Certified}

International Journal of Engineering and Innovative Technology (IJEIT)

Volume 10, Issue 5, November 2020

\section{Transferability of Recommendations and Italian law enforcement and indirectly by tracking of drivers with (ANIA) Practices to Cameroon}

As part of our research objectives, the good practices carried out by insurance companies in developed countries has been studied and in particularly the case study of ANIA in Italy, in addition to those practices pointed out by different authors. It is therefore important in this research to measure the transferability of these good practices to the Cameroon context. The measurement of this transferability is done with the help of a problem priority matrix. The problem matrix used in this study is adapted from Safer Africa transferability audit. It consists of factors influencing road safety transferability, institutions, economy and society (road safety space); identified insurance companies' main role on road safety and the specific practice; scores (S), representing the level of challenge and weight (W), representing the level of priority. This problem matrix was administered to insurance experts including the experts who responded to our initial questionnaires. The responses were given with respect to their degree of competence on specific issues. A combination of the responses to this transferability are presented in Table 8 below (shown in appendix). The legends to the matrix is:

\begin{tabular}{|l|l|}
\hline S represent the scores & W represents weights \\
Likert Scale: $1-5$ & Level of priority: \\
1 least challenging & 1 high \\
5 most challenging & 2 medium \\
& 3 low \\
\hline
\end{tabular}

\section{DISCUSSION}

Discussions will be done according to the results of the role of insurance companies to road safety and the results of the transferability matrix.

\section{A. Role of Insurance Companies to Road Safety in Cameroon}

\section{Contributions to Reduce Accidents}

Analysis of statistics reveals that all insurance companies are involved in educating insured users about road accidents. Sensitization is an important aspect raised by these companies, but with specificity as to the kind of sensitization, sensitization mainly through social media and by social outings. Also, training of workers on road safety, as well as law enforcement to the insured is also raised by a company as a way by which it contributes to reduce road accidents. From the general response, insurance companies are also known for tracking vehicles without any insurance.

This indirectly pushes vehicle owners to purchase insurance and in the case of accidents these vehicle owners can be compensated, therefore insurance companies are contributing to road safety. However, another important conclusion one could draw is that insurance companies primary objectives are not to reduce road accidents, but rather pure traders aiming to maximize profits. In conclusion the insurance companies contribute to road safety directly and indirectly. Directly through education, sensitization and

\section{Pricing Incentives for Safe Driving}

Based on the results obtained, the Bonus Malus procedure is difficult to implement due instability of car customers. We may conclude, then, that this is not an effective way of enhancing road safety and that argument decreases and incentives should in fact not be treated as an effective roadsafety measure but as a marketing tactic. Moreover, drivers who else want to uphold a reputation for safe driving as a token of interest or group spirit while cash incentives are in place cannot differentiate from drivers who take on safe driving for more selfish purposes (i.e. payment). Simply put, the incentive of naturally motivated 'good drivers' is less to hold the motivated conduct, if safety is not reputable, or worse, if a "safe driver' is there for the benefit of money [12]. The results of Jan \& Steg[10]shows that when the financial incentives are removed, drivers returned to their 'natural' speeding level. In conclusion the Bonus Malus system practice is not an efficient road safety intervention practice by insurance companies in Cameroon

Since all tariffs are fixed by the Ministry of Finance, no pricing mechanisms like PAYD, PHYD, and PAHYD exist or is being carried out by insurance companies. Therefore, insurance companies pricing mechanism don't consider the travel and driving behaviour of the drivers and as such their pricing mechanism has no effect on road safety but only remain as a marketing tool.

\section{Road Safety Research}

Results of road safety research show us that there is absence of research on road safety by insurance companies in Cameroon. No new technologies that improve road safety exist, but the seremains as future prospects. Therefore, Cameroon insurance companies are not involved in promoting road safety research.

As concern data management, the main data sources apart from the insured (which is an obligation to the insured in case of claims) is the police/gendarmerie and other available sources are justice and to a lesser extent medical institution.

Concerning furnishing of data for road safety purposes, there is no bilateral exchange of information on road accidents between the insurance companies and police. $0 \%$ also observed for road safety researchers, which could reflect two possibilities, either insurance company doesn't make data available for researchers on road safety or there are no researchers on road safety to ask for such (insurance) data. From our experience while conducting this research, the $0 \%$ reflects both possibilities, because a majority of the companies refused to take part in the survey, while on the other hand the companies that took part in the survey shared their data. However, no company agreed to have furnished data on road safety for the past years, so the leading conclusion is there has been no research on road safety involving insurance companies. 
ISSN: 2277-3754

\section{ISO 9001:2008 Certified \\ International Journal of Engineering and Innovative Technology (IJEIT) \\ Volume 10, Issue 5, November 2020}

\section{Compensation}

The conclusion drawn from this is that insurance companies actively play their role in compensating road accidents victims and as such it is one of their greatest contributions to road safety. Secondly, as concern the respect of the delay stipulated by CIMA code in compensation payments, all the respondents gave a positive answer. Insurance companies therefore contribute to road safety by respecting the delay stipulated in the CIMA code. Thirdly, the results obtained from the procedures to accelerate compensation of victim's shows that, with regard to material damage, the insurance companies have signed an agreement called the IDA, which allows the repair of material damage to their insured parties to be accelerated before appealing to the responsible insurer. In accelerating compensations for victims, insurance companies contribute to road safety by reducing the burden of trauma.

\section{Involvement in National Road Safety Strategy}

Insurance companies are not involved in national road safety strategies on road safety and the surfacing reason to this is that public authorities don't actually involve insurers in decision making. One can therefore confidently say that, there are 'holes' on the national road safety programs as they don't include these private sectors that are directly connected with road accidents. It is also important that insurance companies should be involved in all projects/ decisions concerning road safety as these companies and road accidents are natural allies.

\section{Other Contributions to Improve Road Safety}

Results show that all insurance companies carry out education and publicity as means of reducing road accidents and this represent the highest contributions amongst all other contributions to improve road safety. In addition, driver training and law enforcement is also a means by which insurance companies contribute to road safety. When it comes to voluntary donations and vehicle safety, no insurance company accepted to be involved. In comparison and correlation with results obtained in the first evaluation (contributions by insurance companies to reduce road accidents), the conclusion one can draw is that driver training (insured), education and publicity are the main role played by insurance companies to improve road safety (since the results appeared in both questions) and to a lesser traffic law enforcement and grants and awards. While voluntary donations and vehicle safety is completely out of the list.

\section{B. The Transferability Matrix}

\section{Assessing final problem scores}

- Lowest scores per rows $\rightarrow$ measures least challenging;

- Lowest scores per columns $\rightarrow$ road safety space components least affected.

\section{Assessing final problem weights}

- Lowest weight per rows $\rightarrow$ highest priority amongst different road safety space components in carrying out a specific practice;

- Lowest weight per columns $\rightarrow$ amongst the different specific practice, that particular specific practice is highest priority of for a given road Safety Space components.

With the above comments, analysis of Table 8 is easy. The results of this table speak for itself and remains the decisions of stakeholders, insurance companies and the public authorities to make about implementing a particular strategy to improve road safety. However, the results of the table show that:

- For usage-based insurance practice, it recorded highest amongst other practices, low values for both weight and scores, indicating that the application of this practice is least challenging and is of a high priority to be implemented.

- Sensitization is not of high priority for the society, but however, it's not a more challenging political and insurance commitment, which can be as results of cost affordability despite the presence of the technical knowhow.

- Road safety funding and sponsorship is generally of medium priority, but however results show that this practice is challenging to the society with low cost affordability.

- Road safety research and technology recorded highest, amongst other practices, high values for both weight and scores, showing that it is very challenging and not of high priority. However, when it comes to specific research like data management, it is of high priority to the institutions and least challenging.

- Compensation and rehabilitation general have high values for both weight and scores, showing that this practice is more challenging but of medium priority. However, the highest priority of this practice is recorded for technical availability as all the scores in the columns are of unit value.

- Incentives for safe driving in general recorded low values for both weight and scores indicating this practice is generally not challenging and is of medium priority. It is therefore a good practice to be adopted by insurance companies to tackle the problems of road safety.

- National road safety policy is generally of high priority for the institution and the economy. In terms of scores the practice is generally challenging especially in terms of cost affordability.

- Amongst other specific practice, on board telematics appears to be most challenging in the road safety space.

On our own point of view, also with proof from Table 8 (having low values for both weight and scores), usage-based insurance is the best practice to be implemented in Cameroon. The measure of the problem matrix and its transferability is however a project and a research on its own (future recommendations) and the results suggested here are not $100 \%$ conclusive as it was only the results of few experts. However, it is an important stepping stone and a tool for decision makers to implement given strategies to solve the issues of road safety in relation to insurance companies. 
ISSN: 2277-3754

\section{ISO 9001:2008 Certified \\ International Journal of Engineering and Innovative Technology (IJEIT)}

Volume 10, Issue 5, November 2020

The empty space in Table 8 reflects no direct interaction (in terms of problems) of a specific practice with a given road safety space (with respect to score or weight).

\section{CONCLUSION}

To the best of our knowledge, there is no single study done so far on such issues above in Cameroon's insurance companies, especially on the role of insurance companies in road safety. Most studies identified on road safety in Cameroon, focuses generally on road traffic injuries (RTI) and causes, rather than on specific prevention activities and stakeholders. Hence, we considered that this paper fills the research gap that has been observed, and yet not addressed by those who did their studies on road traffic accident in Cameroon.

In general, an overview of the role of motor insurance industries in road safety shows that insurance companies can be involved in road safety through; effective data management; pricing incentives for safe driving; increase compensation and rehabilitation practices; involvement in national road safety policy; road safety funding and sponsorship; road safety research. Participation of insurance companies in road safety activities will bring two main positive effects; first it compensates the victims of road traffic accident and property therein. Secondly, participating in road safety programs reduces the road traffic accident and hence reducing the social cost of road accidents.

Compensation of road victims was identified as the key aspect by which insurance companies in Cameroon are involved in road safety. However, education, publicity, training of insured and to a lesser extent enforcement and grants were identified as the other ways Cameroonian insurance industries contribute to road safety. Another important result shows that Cameroonian insurance companies are simply pure traders and their businesses are simply compensating road crashes and not being involved in road safety. The results stated clearly shows how Cameroon insurance companies reduce the burden of road accidents.

Last but not the least, the "potential benefits" show the different specific ways or interventions in which Cameroonian motor insurance could be actively involved in road safety and the benefits of its involvement, hence contributing to the global road safety targets. In terms of transferability of good practices to Cameroon insurance companies, usage-based insurance is least challenging, of high priority amongst other good practices and is therefore highly recommended to be practice by Cameroon insurance companies. Research and technology remain a 'common a cry', highly challenging to be implemented in Cameroon.

This study is delimited to the assessment financial and economic impacts of insurance industry in the prevention and compensation of road casualties in Cameroon. This study has encountered problems like low level of willingness from the respondents to be included in the study as well absence and shortage of fully organized data.
The recommendations for future research possibilities on this field include: Using a bottom-up approach to assess the role of insurance companies in road safety in Cameroon (hints: after the implementation of the proposed strategies by which insurance companies can contribute to road safety, the effectiveness of these strategies can be tested an assessed. For each type of insurance strategy that might affect driver's behavior, a suitable sample can be collected and indicator made to measure the behavioral change.).

\section{REFERENCES}

[1] J. Sobngwi-Tambekou, J. Bhatti, G. Kounga, L. R. Salmi, and E. Lagarde, "Road traffic crashes on the Yaounde-Douala road section, Cameroon," Accid. Anal. Prev., vol. 42, no. 2, pp. 422-426, 2010.

[2] G. Jacobs, A. A. Thomas, and A. Astrop, "Estimating Global Road Fatalities,” Transp. Res. Lab., no. December, pp. 36-41, 2000.

[3] J. Zantema, D. H. Van Ameisfort, M. C. J. Bliemer, and P. H. L. Bovy, "Pay-as-you-drive strategies: Case study of safety and accessibility effects," Transp. Res. Rec., no. 2078, pp. 8$16,2008$.

[4] D. I. Tselentis, G. Yannis, and E. I. Vlahogianni, "Innovative motor insurance schemes: A review of current practices and emerging challenges," Accid. Anal. Prev., vol. 98, pp. 139148, 2017.

[5] S. Kantor and T. Stárek, "Design of Algorithms for Payment Telematics Systems Evaluating Driver's Driving Style," Trans. Transp. Sci., vol. 7, no. 1, pp. 9-16, 2014.

[6] G. Dionne, P. C. Michaud, and J. Pinquet, "A review of recent theoretical and empirical analyses of asymmetric information in road safety and automobile insurance," Res. Transp. Econ., vol. 43, no. 1, pp. 85-97, 2013.

[7] D. Mortimer, J. S. Wijnands, A. Harris, A. Tapp, and M. Stevenson, "The effect of smart financial incentives on driving behaviour of novice drivers," Accid. Anal. Prev., vol. 119, no. March, pp. 68-79, 2018.

[8] T. Sayed, P. DeLeur, and Z. Sawalha, "Evaluating the insurance corporation of British Columbia road-safety improvement program,” Transp. Res. Rec., no. 1865, pp. 5763, 2004.

[9] M. H. Junnaidi and M. M. Saleh, "Effects of Motor Insurance Industry and Its Role in Road Safety Management: A Study of Saudi Arabia," Eur. J. Bus. Manag., vol. 9, no. 35, pp. 106$112,2017$.

[10] I. M. A. Alfaki and M. Enaji, "Effect of Motor Insurance Premiums on Driver Behavior and Road Safety," J. Ergon., vol. S3, no. 01, pp:1-7, 2013.

[11] Y. C. Hsu, Y. M. Shiu, P. L. Chou, and Y. M. J. Chen, "Vehicle insurance and the risk of road traffic accidents," Transp. Res. Part A Policy Pract., vol. 74, pp. 201-209, 2015.

[12] J. W. Bolderdijk, J. Knockaert, E. M. Steg, and E. T. Verhoef, "Effects of Pay-As-You-Drive vehicle insurance on young drivers ' speed choice : Results of a Dutch field experiment," Accid. Anal. Prev., vol. 43, no. 3, pp. 1181-1186, 2011.

[13] G. Dionne, P. Michaud, and J. Pinquet, "Research in Transportation Economics A review of recent theoretical and 
ISSN: 2277-3754

ISO 9001:2008 Certified

International Journal of Engineering and Innovative Technology (IJEIT)

Volume 10, Issue 5, November 2020

empirical analyses of asymmetric information in road safety

pp. 85-97, 2013.

and automobile insurance," Res. Transp. Econ., vol. 43, no. 1,

\section{APPENDIX}

Table 7. Potential benefits of implementing recommended strategies to road safety. Adapted from literature review ([4], [8], [12], [13]).

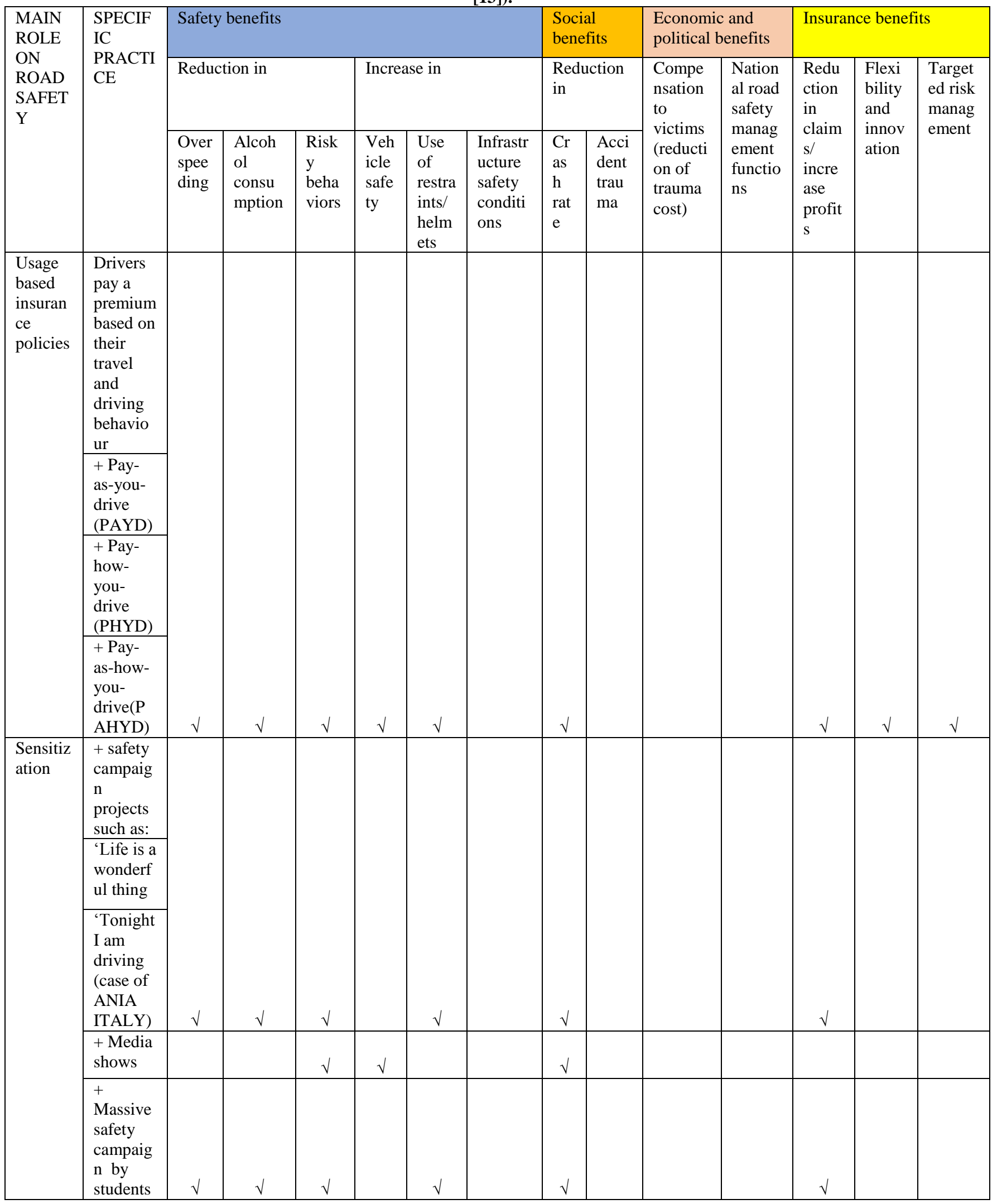




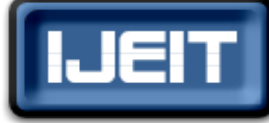

ISSN: 2277-3754

ISO 9001:2008 Certified

International Journal of Engineering and Innovative Technology (IJEIT)

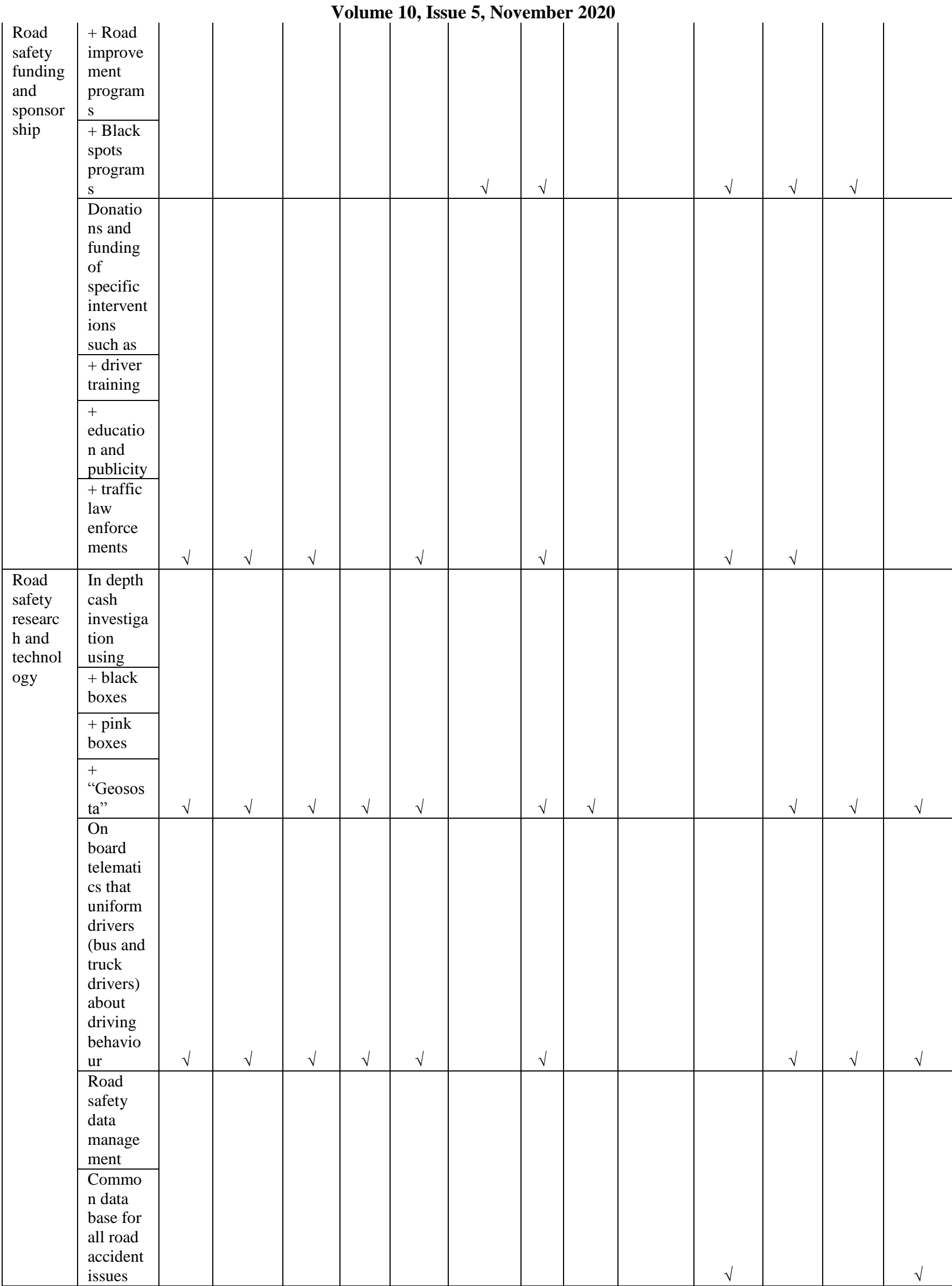


ISSN: 2277-3754

ISO 9001:2008 Certified

International Journal of Engineering and Innovative Technology (IJEIT)

Volume 10, Issue 5, November 2020

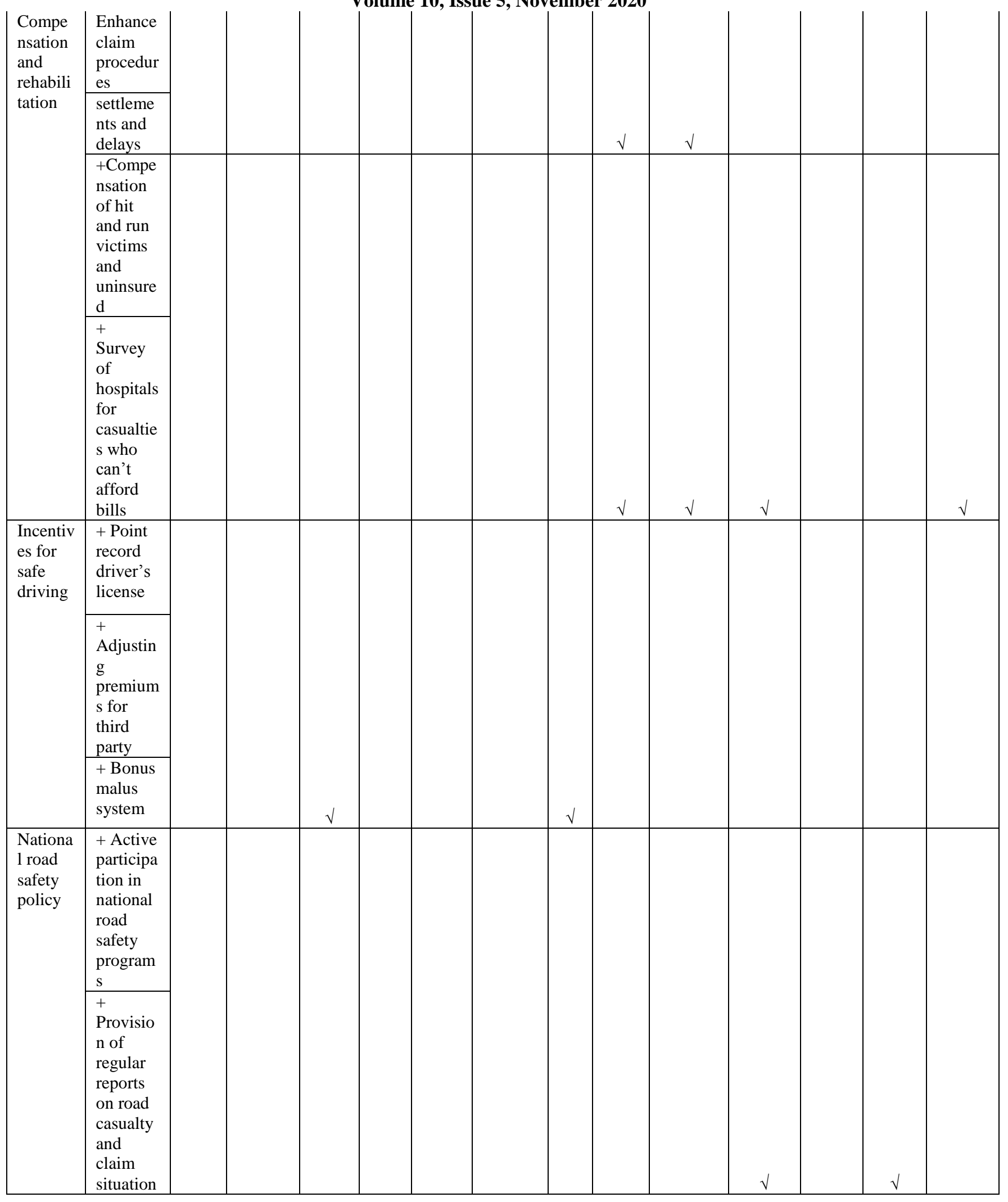




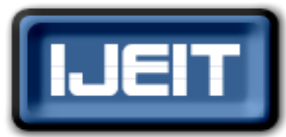

ISSN: 2277-3754

ISO 9001:2008 Certified

International Journal of Engineering and Innovative Technology (IJEIT)

Volume 10, Issue 5, November 2020

$\left|\begin{array}{l}+ \\ \text { Partners } \\ \text { hip with } \\ \text { engineer } \\ \text { ing } \\ \text { universit } \\ \text { ies } \\ \text { concerne } \\ \text { d with } \\ \text { road } \\ \text { safety }\end{array}\right|$

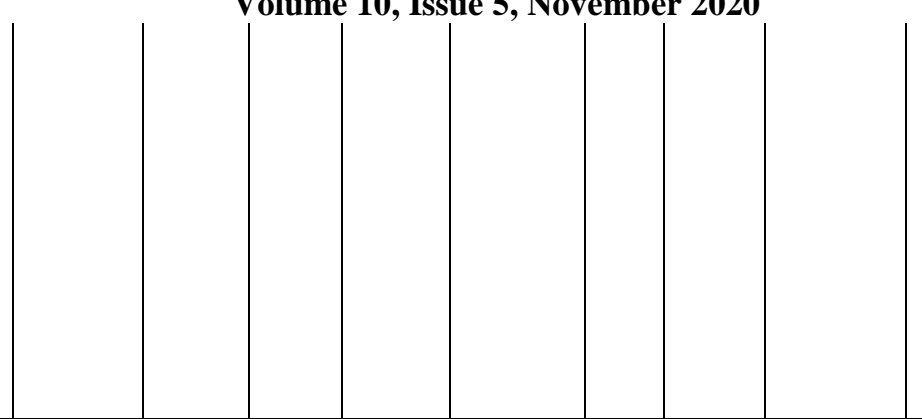

Table 8. Problem priority matrix.

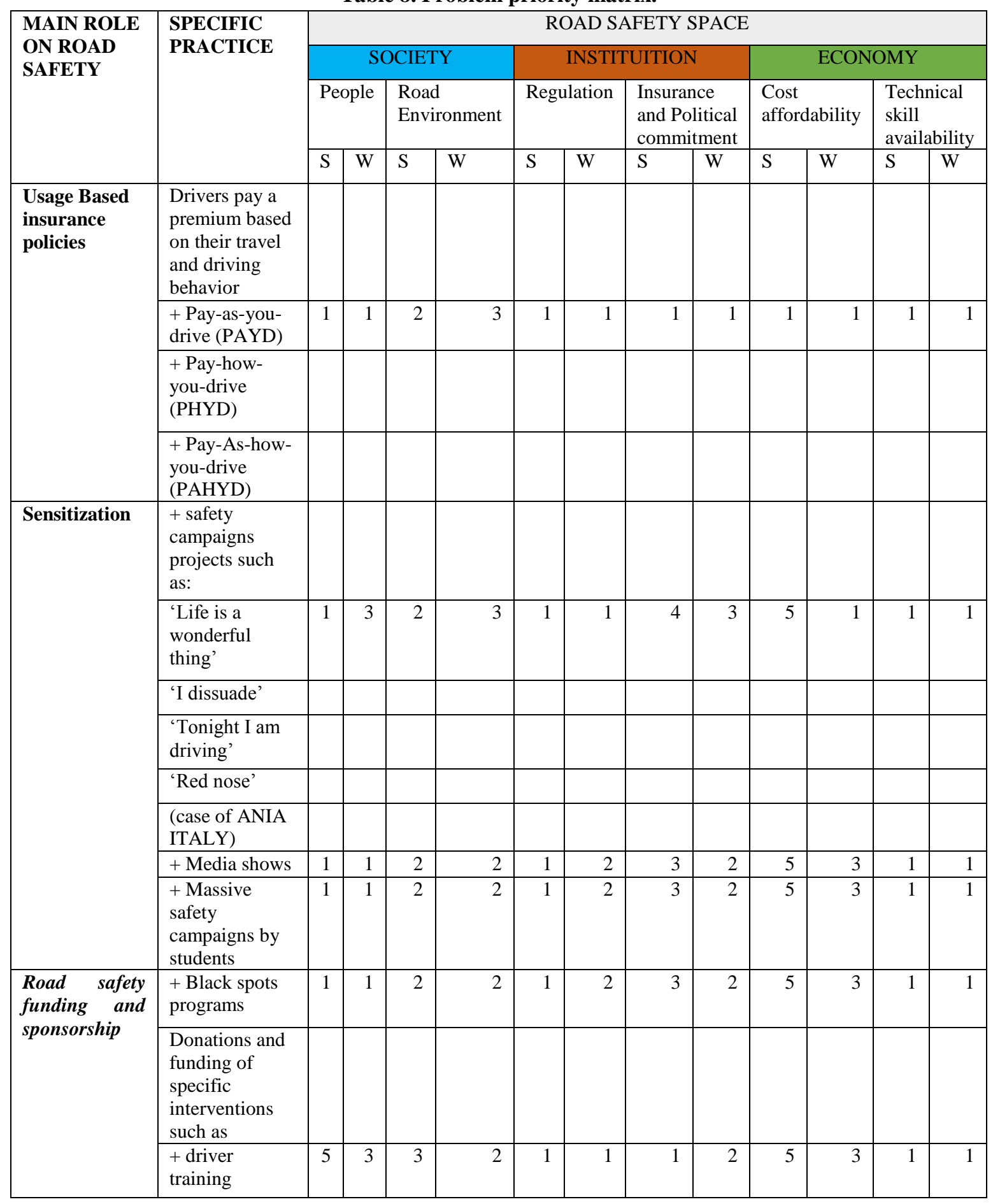




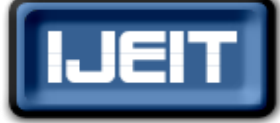

ISSN: 2277-3754

ISO 9001:2008 Certified

International Journal of Engineering and Innovative Technology (IJEIT)

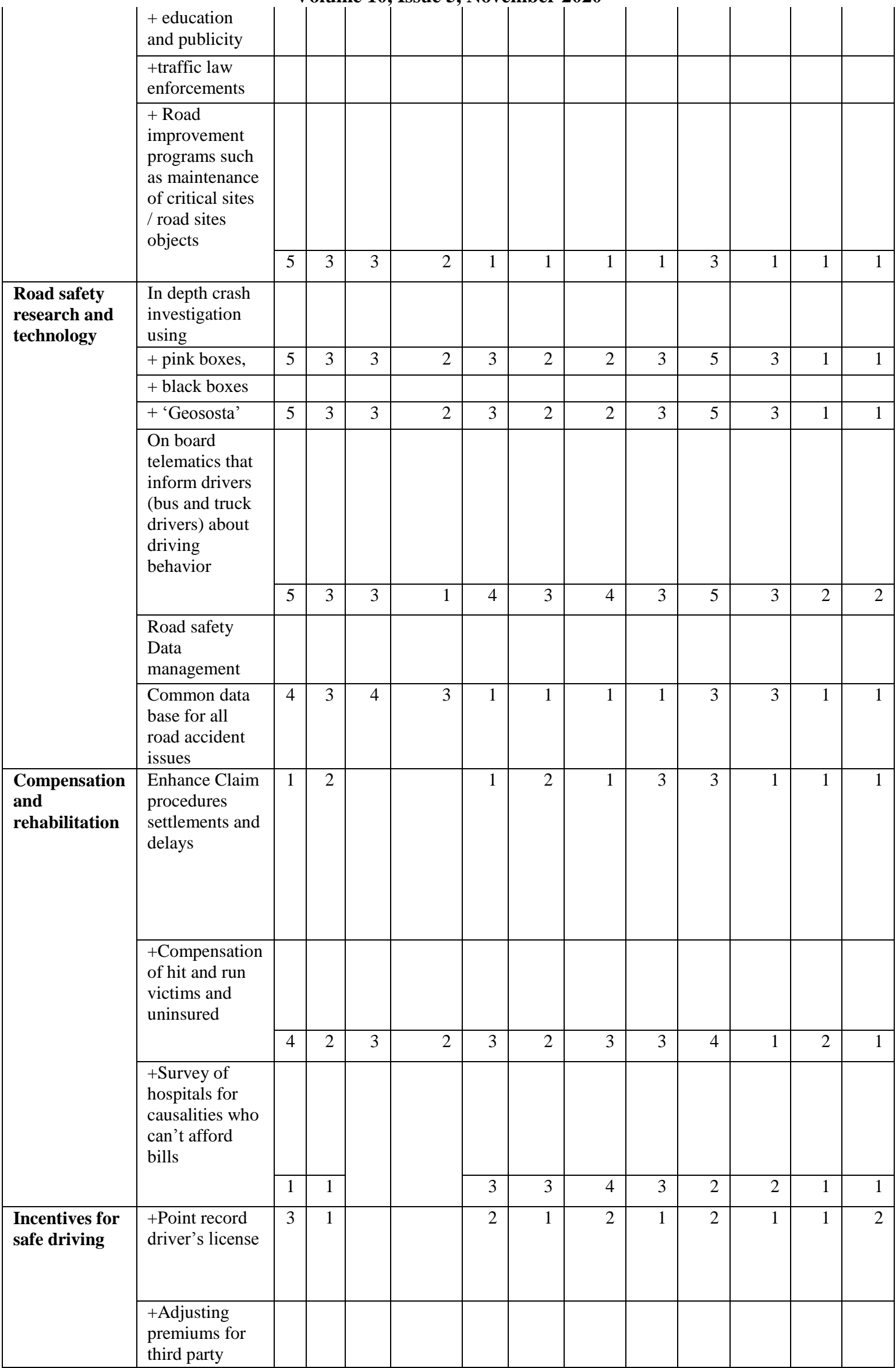


ISSN: 2277-3754

ISO 9001:2008 Certified

International Journal of Engineering and Innovative Technology (IJEIT)

\begin{tabular}{|c|c|c|c|c|c|c|c|c|c|c|c|c|c|}
\hline & \multicolumn{13}{|c|}{ Volume 10, Issue 5, November 2020} \\
\hline & & 2 & 3 & & & 2 & 2 & 2 & 3 & 1 & 1 & 2 & 2 \\
\hline & $\begin{array}{l}\text { +Bonus malus } \\
\text { system }\end{array}$ & & & & & & & & & & & & \\
\hline & & 2 & 1 & & & 2 & 2 & 1 & 2 & 1 & 1 & 1 & 2 \\
\hline $\begin{array}{l}\text { National road } \\
\text { safety policy }\end{array}$ & $\begin{array}{l}+ \text { Active } \\
\text { participation in } \\
\text { national road }\end{array}$ & & & & & & & & & & & & \\
\hline $\begin{array}{l}\text { National road } \\
\text { safety policy }\end{array}$ & programs & 1 & 2 & & & 2 & 1 & 1 & 1 & 3 & 3 & 1 & 1 \\
\hline & $\begin{array}{l}\text { + Provision of } \\
\text { regular reports } \\
\text { on road } \\
\text { casualty and } \\
\text { claim situation } \\
\text { Providing } \\
\text { Psychological } \\
\text { first aid for } \\
\text { victims of road } \\
\text { accident }\end{array}$ & & & & & & & & & & & & \\
\hline & & 4 & 3 & 3 & 3 & 2 & 1 & 2 & 1 & 4 & 2 & 1 & 1 \\
\hline & $\begin{array}{l}\text { + Partnership } \\
\text { with } \\
\text { engineering } \\
\text { universities } \\
\text { concerned with } \\
\text { road safety }\end{array}$ & & & & & & & & & & & & \\
\hline & & 1 & 3 & 1 & 3 & 2 & 1 & 3 & 1 & 3 & 1 & 2 & 1 \\
\hline
\end{tabular}

Note $\mathrm{S}$ represents the Scores (level of challenge) and $\mathrm{W}$ represents the weights (level of priority) 